\title{
Wall-Slip of Highly Filled Powder Injection Molding Compounds: Effect of Flow Channel Geometry and Roughness
}

\author{
Berenika Hausnerova $^{\mathrm{a}, \mathrm{b}}$, Daniel Sanetrnik ${ }^{\mathrm{a}, \mathrm{b}}$, Gordana Paravanova ${ }^{\mathrm{b}}$ \\ ${ }^{a}$ Dept. of Production Engineering, Faculty of Technology, Tomas Bata University in Zlin, nám. T.G.Masaryka 5555, \\ 760 01Zlin, Czech Republic \\ ${ }^{b}$ Centre of Polymer Systems, University Institute, Tomas Bata University in Zlin, Nad Ovčirnou 3685, 76001 Zlin, \\ Czech Republic
}

\begin{abstract}
The paper deals with the rheological behavior of highly filled compounds proceeded via powder injection molding (PIM) and applied in many sectors of industry (automotive, medicine, electronic or military). Online rheometer equipped with slit dies varying in surface roughness and dimensions was applied to investigate the wall-slip as a rheological phenomenon, which can be considered as a parameter indicating the separation of compound components (polymer binder and metallic powder) during high shear rates when injection molded.
\end{abstract}

Keywords: highly filled polymer melt, online rheometer, wall slip, slit die, surface roughness

PACS: 83.50.Rp, 83.80.-k, 47.57.Ng

\section{INTRODUCTION}

Wall slip is a phenomenon occurring often during the flow of multi-phase compounds. It has been generally accepted that upon shearing a thin polymer layer is created near the wall. This layer lubricates the wall on which the bulk material slips during shearing. It becomes thinner as a filler concentration is raised, which might even support the slip effect because particles adhesion to the wall decreases (Figure 1).

The occurrence of wall slip decreases the deformation rate imposed on the compound in comparison to the noslip condition under similar wall shear stress (Kalyon, 1993). The most significant conditions causing the slip effect are strong dependence of viscosity on a filler concentration, large particles as a dispersed phase, smooth flow channel walls and small flow geometry size [1-3].

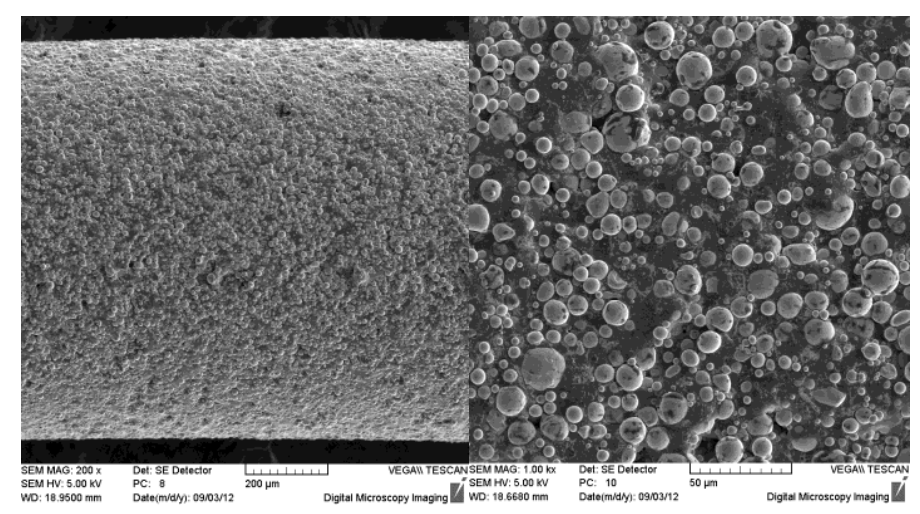

FIGURE 1 Surface of highly filled stainless steel based feedstock C 316L extruded from a capillary rheometer. 
To characterize the wall slip behaviour Mooney [4] proposed a method for evaluation of data from capillary and Couette flow to determine the slip velocity from the slope of the apparent shear rate versus reciprocal diameter or gap data collected at constant wall shear stress. Martin and Wilson [5] later recommended Tikhonov regularization of the method for the capillary data treatment.

Flow modelling of such rheologicaly complicated materials as powder injection molding (PIM) compounds brings many obstacles and limitations because of the multi-component character of polymer binder and complex powder characteristics, mainly irregular shape and broad particle size distribution [6]. An understanding of their rheological behavior with an emphasis on the wall slip might clarify the flow conditions allowing for a phase separation during injection molding step of the process. The purpose of this study is to determine the effect of the geometry and surface roughness of the flow channels on the wall slip, which might provide more realistic simulation of injection molds filling, and finally diminish or prevent defects arising from separation as voids and cracks on the final PIM parts.

\section{EXPERIMENTAL}

Three types of commercially available feedstocks for powder injection molding were used for this study and further analysis. The feedstocks based on the stainless steels 316L and 17-4PH (abbreviated P 17-4PH, P 316L and C 316L) were extruded (Brabender Extrusiongraph 19/25D) through four slit dies (designed at UTB in Zlin) differing in their dimensions and surface roughness measured in transverse direction with Mitutoyo surtest SJ-301 surface roughness analyzer, Table 1.

TABLE 1 Characteristics of slit dies used.

\begin{tabular}{ccc}
\hline $\begin{array}{c}\text { Geometry } \\
{[\mathbf{m m}]}\end{array}$ & $\begin{array}{c}\text { Smooth } \\
\mathbf{R}_{\mathbf{a}}[\boldsymbol{\mu m}]\end{array}$ & $\begin{array}{c}\text { Roughened } \\
\mathbf{R}_{\mathbf{a}}[\boldsymbol{\mu} \mathbf{m}]\end{array}$ \\
\hline $10 \times 0.5 \times 100$ & $0.25 \pm 0.028$ & $0.94 \pm 0.023$ \\
$15 \times 1 \times 100$ & $0.25 \pm 0.012$ & $0.94 \pm 0.041$ \\
\hline
\end{tabular}

As can be seen in Figure 2, the pressure profile was evaluated with the help of five pressure transducers ( $p 5$ applied at the entrance of the slit die and $p 3$ corresponding with exit of the slit die); the sixth transducer was used as a control sensor.

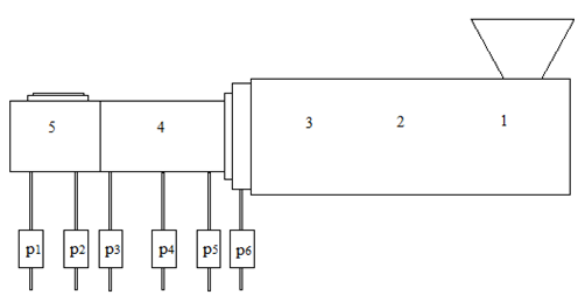

FIGURE 2 A scheme of testing device with pressure transducers (p1-p6) and controlled temperature zones (1-3 - extruder, 4 - slit die and 5 - movable element).

Temperature conditions (Table 2) were set up according to the data sheets of the materials, the screw speeds up to $100 \mathrm{rpm}$ were applied.

TABLE 2 Temperature conditions for tested feedstocks.

\begin{tabular}{cccccc}
\hline Material & $\begin{array}{c}\text { Zone 1 } \\
\text { temperature } \\
{\left[{ }^{\circ} \mathbf{C}\right]}\end{array}$ & $\begin{array}{c}\text { Zone 2 } \\
\text { temperature } \\
{\left[{ }^{\circ} \mathbf{C}\right]}\end{array}$ & $\begin{array}{c}\text { Zone 3 } \\
\text { temperature } \\
{\left[{ }^{\circ} \mathbf{C}\right]}\end{array}$ & $\begin{array}{c}\text { Zone 4 } \\
\text { temperature } \\
{\left[{ }^{\circ} \mathbf{C}\right]}\end{array}$ & $\begin{array}{c}\text { Zone 5 } \\
\text { temperature } \\
{\left[{ }^{\circ} \mathbf{C}\right]}\end{array}$ \\
\hline P 316L & 180 & 185 & 190 & 190 & 190 \\
P 17-4PH & 170 & 180 & 185 & 190 & 190 \\
C 316L & 160 & 170 & 180 & 190 & 190 \\
\hline
\end{tabular}


Shear stress $\tau(\mathrm{Pa})$ was derived from

$$
\tau=\frac{\left(p_{5}-p_{3}\right) \cdot H}{2 L}
$$

where $H(\mathrm{~mm})$ represents the height of the slit die and $L(\mathrm{~mm})$ its length.

Shear rate was calculated according to

$$
\dot{\gamma}_{a}=\frac{6 \dot{Q}}{H^{2} W}
$$

where $W(\mathrm{~mm})$ is the width of the slit die, and $\dot{Q}\left(\mathrm{~mm}^{3} / \mathrm{s}\right)$ stands for the volumetric flow rate.

\section{RESULTS AND DISCUSSION}

All tested materials exhibit pseudoplastic behavior in the measured range of shear rates. The different tendency of the compounds to the wall slip is obtained concerning the effect of surface roughness and slit die dimensions. While for $\mathrm{P} 316 \mathrm{~L}$ no perceptible influence of the surface roughness is found, $\mathrm{P} 17-4 \mathrm{PH}$ exhibits wall slip phenomenon with shear stresses shifted towards lower values at the corresponding shear rates for the smooth geometries and smaller geometry used.

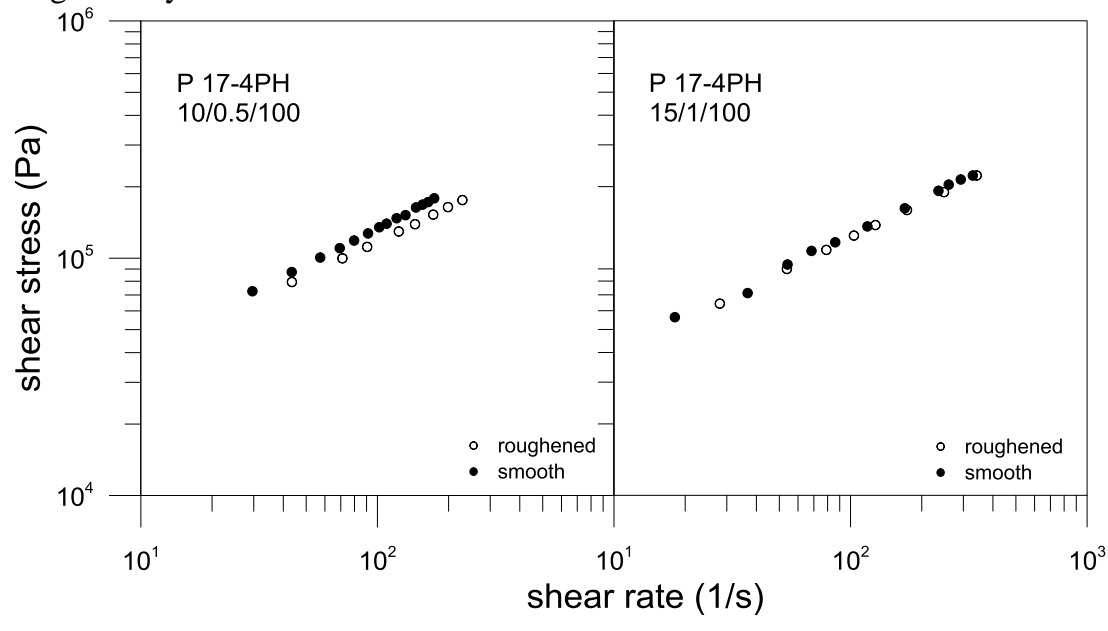

FIGURE 3 Shear stress vs. shear rate of P 17-4PH compound.

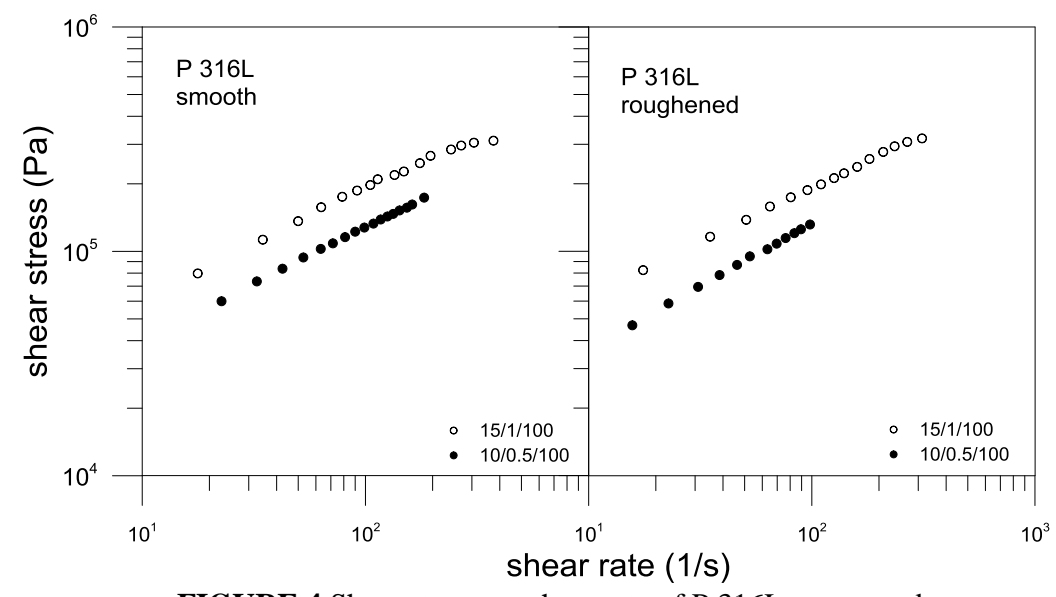

FIGURE 4 Shear stress vs. shear rate of P 316L compound. 
The flow curves should be independent of the geometry parameters used if no slip occurs [5]. However, as can be seen from the figures and also from the non-Newtonian indexes of the tested materials depicted in Table 3 , the rather opposite holds for the PIM feedstocks. Figure 4 demonstrates the strong effect of geometry for P $316 \mathrm{~L}$ for both roughened and smooth surface of the slit dies.

As P 316L and C 316L compounds differed in polymer binder components, while P 316L and P17-4 PH contained the same polymers but differed on powder characteristic, it might be concluded that the tendency of the PIM feedstocks to the wall slip investigated as a parameter of surface roughness and geometry of the flow channel is largely dependent on the composition of the polymer binder, and slightly also on the type of metal powder.

TABLE 3 Index of the non-Newtonian behavior of the feedstocks

\begin{tabular}{cccc} 
Material & $\begin{array}{c}\text { Geometry } \\
{[\mathbf{m m}]}\end{array}$ & Surface & $\begin{array}{c}\text { non- } \\
\text { Newtonian } \\
\text { index [-] }\end{array}$ \\
\hline \multirow{2}{*}{ P 316L } & $15 \times 1 \times 100$ & smooth & 0.49 \\
& $10 \times 0.5 \times 100$ & roughened & 0.49 \\
& & roughened & 0.48 \\
& \multirow{2}{*}{$15 \times 1 \times 100$} & smooth & 0.51 \\
\hline \multirow{2}{*}{ P 17-4PH } & & roughened & 0.46 \\
& \multirow{2}{*}{$10 \times 0.5 \times 100$} & smooth & 0.50 \\
& & roughened & 0.56 \\
\hline \multirow{2}{*}{ C 316L } & $15 \times 1 \times 100$ & smooth & 0.63 \\
& & roughened & 0.53 \\
\hline
\end{tabular}

Further, an analogy with the analysis of the phase separation of these PIM compounds [6] might be provided. The compound P 316L demonstrated higher phase separation coefficient (ranging from 20 to 30 depending on the position in the testing mold) and the standard deviation about \pm 10 , while $\mathrm{C} 316 \mathrm{~L}$ demonstrated phase separation coefficient about 20 independent of the position on the testing mold with rather high reproducibility (standard deviation \pm 2 )

\section{ACKNOWLEDGMENTS}

Sona Mizerakova is acknowledged for the help with the experimental. Operational Program Research and Development for Innovations co-funded by the ERDF and national budget of Czech Republic, within the framework of project Centre of Polymer Systems (reg. number: CZ.1.05/2.1.00/03.0111) and Operational Program Education for Competitiveness co-funded by the European Social Fund (ESF) and national budget of Czech Republic, within the framework of project Advanced Theoretical and Experimental Studies of Polymer Systems (reg. number: CZ.1.07/2.3.00/20.0104) are acknowledged. This study was also supported by the internal grant of TBU in Zlín IGA/FT/2014 funded from the resources of specific university research.

\section{REFERENCES}

1. H.A. Barnes, Journal of Non-Newtonian Fluid Mechanics, 56, 221-251 (2005)

2. A. Yoshimura, R.K. Prud'homme, Journal of Rheology, 32, 53-67 (1988)

3. C.S.Nickerson, J.A. Kornfield, Journal of Rheology, 49, 865-874 (2005)

4. D.M. Kalyon, Journal of Material Processing and Manufacturing Science, 2, 159-184 (2003)

5. P.J. Martin, D.I Wilson, Chemical Engineering Science, 60, 493-502 (2005)

6. T Honek, B. Hausnerova, P. Saha, Polymer Composites, 26, 29-36 (2005)

5. H.A. Barnes, Q.D.Nguyen, Journal of Non-Newtonian Fluid Mechanics, 98, 1-14 (2001)

6. B. Hausnerova, D. Sanetrnik, P. Ponizil, Polymer Composites, 34, 1553-1558 (2013) 